\title{
MOTIVASI PENDAMPING TERHADAP KELOMPOK TANI DI DESA KINUNANG KECAMATAN LIKUPANG TIMUR KABUPATEN MINAHASA UTARA
}

\author{
Ema Rumbrawer \\ Leonardus R. Rengkung \\ Jenny Baroleh
}

\begin{abstract}
This study aims to determine the companion motivation of farmer groups in the village of Kinunang, District Likupang East, North Minahasa District. This study was conducted from May to July 2017. The data used were primary data obtained from each farmer group through direct interviews with 30 (thirty) respondents using questionnaires that were asked to the heads of farmer groups in Kinunang Village in East Likupang Sub-district. Secondary data is obtained directly from books, and articles. The data obtained will be analyzed using descriptive analysis which each answer is tested and tested using Likert scale. The results of this study indicate that the motivation of farmer group supporters is very important in the empowerment of farmer groups both at the level of beginner and advanced in the activity.
\end{abstract}

Keywords: companion motivation, farmer group, Kinunang Village, Wori Sub-district, North Minahasa Regency.

\begin{abstract}
ABSTRAK
Penelitian ini bertujuan untuk mengetahui motivasi pendamping terhadap kelompok tani yang ada di Desa Kinunang, Kecamatan Likupang Timur, Kabupaten Minahasa Utara. Penelitian ini dilaksanakan pada bulan Mei sampai dengan Juli 2017. Data yang digunakan adalah data primer yang diperoleh dari masing-masing kelompok tani melalui wawancara langsung dengan 30 (tiga puluh) orang responden dengan menggunakan kuesioner yang ditanyakan kepada ketua-ketua kelompok tani di Desa Kinunang, Kecamatan Likupang Timur. Data sekunder diperoleh langsung dari buku dan artikel-artikel. Data yang diperoleh dianalisis menggunakan analisis deskriptif dan menggunakan skala likert. Hasil penelitian ini menunjukan bahwa motivasi pendamping kelompok tani sangat berperan peting dalam pemberdayaan kelompok tani baik pada tingkat pemula maupun tingkat lanjut dalam pelaksanaan kegiatan.
\end{abstract}

Kata kunci: motivasi pendamping, kelompok tani, Desa Kinunang, Kecamatan Likupang Timur, Kabupaten Minahasa Utara.

\section{PENDAHULUAN}

\section{Latar Belakang}

Pertanian adalah salah satu sektor yang mendukung perekonomian negara. Namun seiring berjalannya waktu dengan munculnya sektor-sektor pendukung lain di Indonesia, secara perlahan pertanian mulai tergeser mengarah pada minat baru sehingga sangat berpengaruh pada petani itu sendiri dan berdampak pada menurunnya produksi dalam setiap usaha pertanian. Pertanian sendiri memiliki subsektor yang terkait antara lain: perkebunan, peternakan, perikanan, dan 
kehutanan semuanya saling berkaitan dalam pengembangan sumber daya alam (SDA). Pemberdayaan masyarakat merupakan suatu upaya untuk memberikan kemampuan sekaligus kesempatan kepada masyarakat untuk berperan aktif dalam proses pembangunan. Pemberdayaan masyarakat adalahpenyadaran akan bakat atau kemampuan, kemandirian dan komitmen.Pemberdayaan masyarakat akan meningkatkan masyarakat dalam mengarahkan, mengendalikan, membentuk dan mengelola hidupnya (Sudjana, 2001). Kegiatan pendampingan terhadap masyarakat kelompok tani lebih banyak diawali oleh LSM (Lembaga Swadaya Masyarakat) melalui programprogram pembangunan masyarakat, Kelompok tani yang adasekarang masih dalam kelompok tani tradisional maupun kelompok tani modern. Pemberdayaan membentuk individu dan masyarakat menjadi mandiri. Kemandirian tersebut meliputi kemandirian berpikir, bertindak dan mengendalikan apa yang dilakukan. Kemandirian masyarakat merupakan suatu kondisi yang dialami oleh masyarakat dengan kemampuan memikirkan, memutuskan serta melakukan sesuatu yang dipandang tepat demi mencapai pemecahan masalah yang dihadapi dengan mempergunakan daya/ kemampuan yang dimiliki.

Kegiatan penyuluhan merupakan salah satu kegiatan untuk mengakselerasi atau memberdayakan petani dan selain kegiatan penyuluhan yang dilakukan oleh penyuluh ada juga kegiatan penyuluhan yang dilakukan oleh tenaga pendamping. Pendamping dihadirkan karena keterkaitan dengan perhatian pemerintah dalam meningkatkan produksi pertanian masyarakat. Pemberdayaan petani dilakukan melalui pelatihan dan pendampingan, akan tetapi keberhasilan kegiatan tersebut yang dilakukan di lapangan harus di dukung oleh pemerintah dan petani selaku penerima bimbingan pemberdayaan agar supaya tujuan dapat tercapai, Berdasarkan pemantauan selama ini motivasi petani didesa kinunang tidak termotivasi oleh karena mereka hanya mengandalkan kemampuan dan pengalaman mereka sendiri, padahalnya belum bisa dihampak. Berdasarkan pemantauan maupun pengamatan dari masyarakat umum, menyatakan bahwa sumberdaya yang rendah, tidak termotivasi bahkan kurangnya tingkat pengetahuan dan atau pendidikan/pelatihan menyebabkan petani kurang termotivasi dalam berusahatani. Kelompok tani di Kecamatan Likupang Timur saat ini kurang maksimalbaik dalam lingkungan maupun kelompok tani yang sudah ada, namun masyarakat desa yang ada berusaha untuk melakukan kegiatan yang bahkan sudah diberikan oleh pemerintah desa supaya dapat mengubah sebagian yang belum baik, bahkan saat ini sudah ada perubahanperubahan, Kelompok tani dapat membangun dan mengembangkan kelompok masyarakat supaya dapat berpartisipasi pada kegiatan lingkungan. Keberadaan kelompok saat ini sangat penting bagi masyarakat desa setempat dan meningkatkan kapasitas sumberdaya manusia.

\section{Rumusan Masalah}

Pemberdayaan adalah salah satu upaya penting dalam merubah perilaku petani sehingga berdasarkan latar belakang, yang menjadi rumusan masalah dalam penelitian ini :

1. Bagaimana motivasi dari pendamping dalam pemberdayaan kelompok tani di Desa Kinunang Kecamatan Likupang Timur Kabupaten Minahasa Utara?

2. Apa kendala yang dihadapi oleh pendamping dalam pemberdayaan kelompok tani di Desa Kinunang Kecamatan Likupang Timur Kabupaten Minahasa Utara?

\section{Tujuan Penelitian}

Berdasarkan latar belakang dan perumusan masalah, maka tujuan penelitian ini untuk mengetahui :

1. motivasi pendamping dalam pemberdayaan kelompok tani di Desa Kinunang Kecamatan Likupang Timur Kabupaten Minahasa Utara.

2. berbagai kendala yang dihadapi pendamping dalam kegiatan pemberdayaan kelompok tani di Desa Kinunang Kecamatan Likupang Timur Kabupaten Minahasa Utara. 


\section{Manfaat Penelitian}

Penelitian ini diharapkan bermanfaat bagi pendamping dan kelompok tani maupun masyarakat. Sebagai bahan informasi bagi kelompok tani dalam upaya pengembangan hasil dan mutu produksi pertanian dan sebagai bahan informasi bagi pemerintah dalam menentukan kebijakan untuk upaya peningkatan kesejahteraan petani dan bagi peneliti sebagai penerapan teori dan konsep yang telah dipelajari selama studi.

\section{METODOLOGI PENELITIAN}

\section{Waktu dan Tempat Penelitian}

Penelitian ini dilakukan di Desa Kinunang, Kecamatan Likupang Timur Kabupaten Minahasa Utara. Penelitian berlangsung selama 3 (tiga) bulan mulai dari bulan Mei sampai dengan Juli 2017, mulai dari persiapan proposal, pengambilan data sampai dengan penulisan laporan penelitian.

\section{Metode Pengumpulan Data}

Metode pengumpulan data yang digunakan yaitu data primer yang diperoleh melalui wawancara langsung dengan kelompok tani yang mendapatkan pendampingan dalam usaha kelompok tani di Desa Kinunang. Data sekunder diperoleh dari beberapa sumber diantaranya dari pemerintah desa dan kecamatan dan sumber data lainnya yang diperoleh dari buku dan internet.

\section{Konsep Pengukuran Variabel}

Pengukuran motivasi kerjadengan melihat pada beberapa aspek antara lain sebagai berikut:

1. Tingkat Agresif, merupakan bentuk perilaku yang dimaksud menyakiti seseoran baik secara fisik maupun mental.

2. Tingkat Kreatif, adalah kemauan untuk mengembangkan atau menciptakan ide dan cara baru yang berbeda dari sebelumnya.

3. Tingkat inisiatif, merupakan konsep awal dasar dalam proses membentuk kemauan.

4. Tingkat mutu pekerjaan, yaitu pekerjaan yang dilaksanakan agar menghasilkan sesuatu yang memang dikehendaki.
5. Tingkat mematuhi jam kerja, adalah kegiatan yang bersifat kedisiplinan diri individu serta kelompok.

\section{Metode Pengambilan Sampel}

Populasi adalah jumlah kelompok tani dalam pemberdayaan kelompok tani yang berjumlah 10 kelompok tani yang berada di Desa Kinunang dan sampel diambil secara acak (simple random sampling) tiap kelompok tani 3 orang sehingga responden berjumlah 30 orang.

\section{Metode Analisis Data}

Analisis data dalam penelitian ini yaitu secara deskriptif dengan disajikan menggunakan tabel dan angka. Setiap jawaban dihubungkan dengan bentuk pernyataan atau dukungan sikap yang diungkapkan dengan kata-kata berikut:

$\begin{array}{lr}\text { Sangat kuat } & \text { Skor 5 } \\ \text { Kuat } & \text { Skor 4 } \\ \text { Netral } & \text { Skor 3 }\end{array}$

Sedang Skor 2

Tidak kuat Skor 1

\section{HASIL DAN PEMBAHASAN}

\section{Gambaran umum Wilayah Penelitian}

\section{Letak Wilayah Geografis}

Desa Kinunang merupakan salah satu desa yang terletak dibagian timur dari Kecamatan Likupang Timur Kabupaten Minahasa Utara dengan luas wilayah $\pm 500 \mathrm{Ha}$ dengan batas wilayah sebagai berikut:

- Sebelah Utara berbatasan dengan : Selat Bangka

- Sebelah Timur berbatasan dengan : Selat Lembe

- Sebelah Selatan berbatasan dengan : PTPN VIII

Afdeling

Marinsow

- Sebelah Barat berbatasan dengan : Desa Pulisan

\section{Kondisi Demografi}

Data demografi Desa Kinunang tahun 2017 memiliki jumlah penduduk sebanyak 309 jiwa, yang terdiri dari laki-laki 156 jiwa dan perempuan terdiri dari 153 jiwa. Adapun mata pencaharian penduduk desa ini cukup beragam yaitu sebagai petani, buruh tani, PNS/Guru, pegawai swasta, wiraswasta, tukang jahit, sopir, peternak/nelayan, mahasiswa, pelajar, TNI/Polri, dan Pensiunan. 
Tabel 1. Jumlah Penduduk Menurut Mata Pencaharian

\begin{tabular}{|c|c|c|}
\hline $\begin{array}{c}\text { Mata } \\
\text { Pencaharian }\end{array}$ & $\begin{array}{c}\text { Jumlah } \\
\text { Penduduk } \\
\text { (jiwa) }\end{array}$ & $\begin{array}{c}\text { Persentasi } \\
(\%)\end{array}$ \\
\hline Petani & 148 & 51,38 \\
\hline Peternak/Nelayan & 60 & 20,83 \\
\hline Mahasiswa & 37 & 12,85 \\
\hline Swasta & 27 & 9,37 \\
\hline TNI/Polri & 1 & 0,35 \\
\hline Guru & 3 & 1,04 \\
\hline Wiraswasta & 8 & 2,78 \\
\hline Buruh Tani & - & - \\
\hline Pensiunan & - & - \\
\hline Tukang Jahit & 2 & 0,70 \\
\hline Sopir & 2 & 0,70 \\
\hline PNS & - & - \\
\hline Jumlah & 288 & 100 \\
\hline
\end{tabular}

Sumber : Diolah dari Data Sekunder 2017

Tabel 1 menunjukkan jumlah penduduk dan mata pencaharian penduduk Desa Kinunang. Berdasarkan Tabel 1, dapat dilihat bahwa, sebagian besar penduduk Desa Kinunang bekerja disektor pertanian, yaitu sebanyak 148 jiwa $(51,38 \%)$ dan penduduk yg berprofesi peternak/nelayan sebanyak 60 jiwa dalam 20,83

\section{Karakteristik Kelompok Tani}

Kelompok tani yang ada di Desa Kinunang Kecamatan Likupang Timur terdiri dari 10 kelompok tanidengan karateristik kelompok tani meliputi: nama kelompok tani, tahun berdiri, jenis usaha, jumlah anggota, nama ketua kelompok tani, dan tingkat pendidikan, Petani di masing- masing kelompok yang dapat diambil adalah ketua kelompok tani dimasing-masing kelompok. Lebih jelasnya dapat dilihat pada Tabel 2.
Tabel 2. Karakteristik Kelompok Tani di Desa Kinunang

\begin{tabular}{|c|c|c|c|c|c|c|}
\hline No & $\begin{array}{l}\text { Nama } \\
\text { Kelompok } \\
\text { Tani }\end{array}$ & $\begin{array}{l}\text { Tahun } \\
\text { Berdiri }\end{array}$ & $\begin{array}{c}\text { Jenis } \\
\text { Usaha }\end{array}$ & $\begin{array}{l}\text { Jumlah } \\
\text { Anggota } \\
\text { (Orang) }\end{array}$ & $\begin{array}{c}\text { Nama } \\
\text { Ketua } \\
\text { Klpk } \\
\text { Tani }\end{array}$ & $\begin{array}{c}\text { Tingkat } \\
\text { Pendidika } \\
\text { n }\end{array}$ \\
\hline 1 & Berkat & 2013 & Jagung & 15 & $\begin{array}{l}\text { Rusmans } \\
\text { et } \\
\text { Nalurapa } \\
\text { ese }\end{array}$ & SMA \\
\hline 2 & Pelita & 2015 & $\begin{array}{l}\text { Kacang } \\
\text { Hijau }\end{array}$ & 10 & $\begin{array}{l}\text { Saskar } \\
\text { Piter }\end{array}$ & SD \\
\hline 3 & Usbar & 2016 & $\begin{array}{l}\text { Kacang } \\
\text { Tanah }\end{array}$ & 15 & Hermens & SMP \\
\hline 4 & Masa & 2013 & Cabe & 10 & $\begin{array}{l}\text { Frets } \\
\text { Bayeli }\end{array}$ & SMA \\
\hline 5 & Anugrah & 2015 & Kedelai & 15 & Sulastri & SD \\
\hline 6 & Sukacita & 2015 & Kopra & 15 & $\begin{array}{l}\text { Josafat } \\
\text { Antara }\end{array}$ & SMA \\
\hline 7 & $\begin{array}{l}\text { Tunas } \\
\text { Harapan }\end{array}$ & 2016 & $\begin{array}{l}\text { Padi } \\
\text { Ladang }\end{array}$ & 15 & $\begin{array}{l}\text { Heldoma } \\
\mathrm{n} \\
\text { Horman }\end{array}$ & SMP \\
\hline 8 & $\begin{array}{l}\text { Singkana } \\
\text { ung }\end{array}$ & 2013 & $\begin{array}{l}\text { Padi } \\
\text { Ladang }\end{array}$ & 15 & $\begin{array}{l}\text { Jesaya } \\
\text { Masare }\end{array}$ & SMA \\
\hline 9 & $\begin{array}{l}\text { Jati } \\
\text { Merah }\end{array}$ & 2013 & Jagung & 15 & $\begin{array}{l}\text { Fredik } \\
\text { Tumei }\end{array}$ & SMP \\
\hline 10 & Prasarana & 2014 & Kedelei & 10 & $\begin{array}{l}\text { Alpius } \\
\text { Togelang }\end{array}$ & SD \\
\hline
\end{tabular}

Sumber : Diolah dari Data Primer 2017

\section{Karakteristik Responden}

Karakteristik responden meliputi nama, umur, jenis kelamin, jabatan dalam kelompok, pekerjaan, dan tingkat pendidikan.

\section{Umur Responden}

Umur bisa mempengaruhi kemampuan seseorang dalam melakukan suatu aktifitas dalam bertindak maupun berpikir. Dan responden dibagi menjadi 4 kelompok umur yaitu 20-35 tahun 36-50 tahun 51- 65 tahun > 66 tahun untuk lebih jelasnya dapat dilihat dalam Tabel 3.

\section{Tabel 3. Umur Responden}

\begin{tabular}{cccc}
\hline No & $\begin{array}{c}\text { Umur } \\
\text { (Tahun) }\end{array}$ & $\begin{array}{c}\text { Jumlah } \\
\text { responden } \\
\text { (orang) }\end{array}$ & $\begin{array}{c}\text { Persentase } \\
(\%)\end{array}$ \\
\hline 1 & $20-35$ & 9 & 30,00 \\
2 & $36-50$ & 12 & 40,00 \\
3 & $51-65$ & 5 & 16,67 \\
5 & $>66$ & 4 & 13,33 \\
\hline Jumlah & & $\mathbf{3 0}$ & $\mathbf{1 0 0}$ \\
\hline
\end{tabular}


Tabel 3, menunjukkan bahwa kelompok umur 36 sampai 50 tahun memiliki jumlah responden terbanyak sebesar 12 responden dengan persentase $40 \%$. Hal ini menunjukkan bahwa sebagian besar responden dapat dikatakan masih dalam usia produktif.

\section{Tingkat Pendidikan}

Tingkat Pendidikan meliputi pengajaran keahlian khusus dan juga sesuatu yang tidak dapat dilihat lebih mendalam yaitu pemberian pengetahuan, pertimbangan dan kebijaksanaan. Dengan adanya pendidikan maka dapat memanfaatkan sarana pendidikan yang ada dimana tingkat pendidikan sangat mempengaruhi terhadap kualitas berfikir, sikap dan bertingkah laku masyarakat dalam menjalani kehidupan mereka sehari-hari, yang tentunya juga akan mempengaruhi seseorang dalam mengambil keputusan dimana mereka melakukan aktifitas. Berikut hasil dari karakteristik responden berdasarkan tingkat pendidikan disajikan pada Tabel 4:

Tabel 4. Jumlah Responden Menurut Tingkat Pendidikan

\begin{tabular}{llcc}
\hline No & $\begin{array}{l}\text { Tingkat } \\
\text { Pendidikan }\end{array}$ & $\begin{array}{c}\text { Jumlah } \\
\text { Responden } \\
\text { (Orang) }\end{array}$ & $\begin{array}{c}\text { Persentase } \\
\text { (\%) }\end{array}$ \\
\hline 1 & SD & 14 & 46,67 \\
2 & SMP & 7 & 23,33 \\
3 & SMA & 9 & 30,00 \\
\hline Jumlah & & 30 & 100 \\
\hline
\end{tabular}

Tabel 4, menunjukkan bahwa tingkat pendidikan petani responden di Desa Kinunang memiliki tingkat pendidikan rata-rata yang terbanyak yaitu $46,67 \%$ pada tingkat Pendidikan Sekolah Dasar (SD) sedangkan 23,33\% berada pada tingkat pendidikan SMP dan pada tingkat pendidikan SMA hanya mencapai $30 \%$. Hal ini menunjukkan bahwa masih sangat rendahnya tingkat pendidikan masyarakat di daerah tersebut.

\section{Pekerjaan Responden}

Pekerjaan dari responden yaitu 100\% petani yang memiliki tanaman seperti jagung, kacang hijau, kacang tanah, cabe, kedele, kopra dan padi ladang. Para petani mengelolahnya walaupun dalam kebun sendiri, namun petani memiliki tanaman lain untuk menunjang hidup bahkan seluruh responden selain petani mereka mempunyai pekerjaan sampingan yaitu sebagai nelayan.

\section{Motivasi Pendamping Terhadap Pemberdayaan Kelompok Tani Di Desa Kinunang Kecamatan Likupang Timur Minahasa Utara}

Kegiatan pendampingan adalah suatu kegiatan yang rutin dilakukan oleh tenaga kerja pendamping pada kelompok tani binaan. Dari kegiatan pendamping ini berupa kegiatan melaksanakan penyuluhan pertanian khususnya pada tanaman masing-masing komoditi agar petani mampu mengorganisasikan dirinya dalam mengakses kepasar, teknologi, permodalandan sumber daya lainnya. Penyuluhan merupakan sarana kebijakan yang dapat digunakan pemerintah untuk mendorong pembangunan pertanian. Dilain pihak petani mempunyai kebebasan untuk menerima atau menolak saran yang diberikan oleh pendamping dalam kegiatan penyuluhan. Dengan demikian pendamping hanya dapat mencapai sasarannya jika perubahan benar-benar menjadi keinginan dan kepentingan dari petani. Dalam kegiatan pendampingan diharapkan program-program yang disampaikan hendaknya sesuai dengan permasalahan yang dihadapi petani juga bermanfaat dengan waktu yang lebih intensif dalam peningkatan usaha tani. Dengan demikian akan terbentuk kerjasama yang baik dimana pendamping menjadi kebutuhan bagi kelompok tani. Berikut ini hasil penelitian tentang motivasi pendamping terhadap pemberdayaan kelompok tani di Desa Kinunang Kecamatan Likupang Timur Minahasa Utara.

\section{Tingkat Agresif}

Tingkat agresif merupakan bentuk perilaku yang menyakiti. Dalam perbentukan agresif juga dapat membangun kehidupan sosial masyarakat. 
Tabel 5. Menjelaskan Tentang Pendamping Cepat Menjawab Dalam Kelompok Tani

\begin{tabular}{lcccc}
\hline $\begin{array}{l}\text { Alternatif } \\
\text { Jawaban }\end{array}$ & $\begin{array}{c}\text { Alternatif } \\
\text { Skor }\end{array}$ & $\begin{array}{c}\text { Jumlah } \\
\text { Responden } \\
\text { (Orang) }\end{array}$ & $\begin{array}{c}\text { Persentase } \\
(\%)\end{array}$ & $\begin{array}{c}\text { Total } \\
\text { Skor }\end{array}$ \\
\hline Sangat Kuat & 5 & 14 & 47 & 70 \\
Kuat & 4 & 10 & 33 & 40 \\
Netral & 3 & 6 & 20 & 18 \\
Sedang & 2 & - & - & - \\
Tidak Kuat & 1 & - & - & - \\
\hline Total & & $\mathbf{3 0}$ & $\mathbf{1 0 0}$ & $\mathbf{1 2 8}$ \\
\hline
\end{tabular}

Tabel 5 menunjukkan bahwa $47 \%$ responden (14 orang) kuat sedangkan 33\% responden (10 orang) sangat kuat dan $20 \%$ responden (6 orang) netral/cukup setuju. Karena indeks mengenai pernyataan nomor 1 yaitu pendamping cepat menjawab sehingga interpretasi nilainya tergolong sangat kuat.

Tabel 6. Pendamping Cepat Menyelesaikan Tugas Atas Standar

\begin{tabular}{ccccc}
\hline $\begin{array}{c}\text { Alternatif } \\
\text { Jawaban }\end{array}$ & $\begin{array}{c}\text { Alternatif } \\
\text { Skor }\end{array}$ & $\begin{array}{c}\text { Jumlah } \\
\text { Responden } \\
\text { (Orang) }\end{array}$ & $\begin{array}{c}\text { Persentase } \\
(\%)\end{array}$ & $\begin{array}{c}\text { Total } \\
\text { Skor }\end{array}$ \\
\hline Sangat & 5 & 25 & 83.33 & 125 \\
Kuat & & & & \\
Kuat & 4 & 5 & 16,67 & 20 \\
Netral & 3 & - & - & - \\
Sedang & 2 & - & - & - \\
Tidak & 1 & - & - & - \\
Kuat & & & & \\
\hline Total & & $\mathbf{3 0}$ & $\mathbf{1 0 0}$ & $\mathbf{1 4 5}$ \\
\hline
\end{tabular}

Tabel 6, menunjukan bahwa 83,33\% responden (25 orang) sangat kuat sedangkan $16,67 \%$ responden (5 orang) kuat. Karena indeks mengenai pernyataan nomor 2 yaitu pendamping cepat menyelesaikan tugas atas standar tergolong sangat kuat.

Tabel 7. Pendamping Cepat Menyelesaikan Masalah

\begin{tabular}{lcccc}
\hline $\begin{array}{l}\text { Alternatif } \\
\text { Jawaban }\end{array}$ & $\begin{array}{c}\text { Alternatif } \\
\text { Skor }\end{array}$ & $\begin{array}{c}\text { Jumlah } \\
\text { Responden } \\
\text { (Orang) }\end{array}$ & $\begin{array}{c}\text { Persentase } \\
(\boldsymbol{\%})\end{array}$ & $\begin{array}{c}\text { Total } \\
\text { Skor }\end{array}$ \\
\hline Sangat & 5 & 16 & 53,33 & 80 \\
Kuat & 4 & 13 & 43,33 & 52 \\
Kuat & 3 & 1 & 3,33 & 3 \\
Netral & 2 & - & - & - \\
Sedang & 1 & - & - & - \\
Tidak & & & & \\
Kuat & & $\mathbf{3 0}$ & $\mathbf{1 0 0}$ & $\mathbf{1 3 5}$ \\
\hline Total & & & & \\
\hline
\end{tabular}

Tabel 7, menunjukkan bahwa 53,33\% responden (16 orang) sangat kuat sedangkan $43,33 \%$ responden (13 orang)kuat 3,33\% responden ( 1 orang) netral karena indeks mengenai pernyataan nomor 3 yaitu pendamping cepat menyelesaikan masalah, sehingga interpretasi nilainya tergolong sangat kuat.

Tabel 8. Pendamping Cepat Mengambil Keputusan

\begin{tabular}{lcccc}
\hline $\begin{array}{l}\text { Alternatif } \\
\text { Jawaban }\end{array}$ & $\begin{array}{c}\text { Alternatif } \\
\text { Skor }\end{array}$ & $\begin{array}{c}\text { Jumlah } \\
\text { Responden } \\
\text { (Orang) }\end{array}$ & $\begin{array}{c}\text { Persentase } \\
(\%)\end{array}$ & $\begin{array}{c}\text { Total } \\
\text { Skor }\end{array}$ \\
\hline $\begin{array}{l}\text { Sangat } \\
\text { Kuat }\end{array}$ & 5 & 15 & 50,00 & 75 \\
Kuat & 4 & 11 & 36,67 & 44 \\
Netral & 3 & 4 & 13,33 & 12 \\
Sedang & 2 & - & - & - \\
Tidak & 1 & - & - & - \\
Kuat & & & & \\
\hline Total & & $\mathbf{3 0}$ & $\mathbf{1 0 0}$ & $\mathbf{1 3 1}$ \\
\hline
\end{tabular}

Tabel 8, menunjukkan bahwa 50\% responden (15 orang) sangat kuat sedangkan $36,67 \%$ responden (11 orang) kuat dan $13,33 \%$ responden (4 orang) netral/cukup kuat. Karena indeks skor tertinggi dari pernyataan nomor 4 yaitu pendamping cepat mengambil keputusan sehingga interpretasi nilainya tergolong sangat kuat.

\section{Tingkat Kreatif}

Kreatif mampu mengembangkan atau menciptakan ide dan cara baru dalam kelompok dapat dilihat pada Tabel 9.

Tabel 9. Pendamping Cepat Memberikan Informasi Tentang Hal yang Baru

\begin{tabular}{lcccc}
\hline $\begin{array}{l}\text { Alternatif } \\
\text { Jawaban }\end{array}$ & $\begin{array}{c}\text { Alternatif } \\
\text { Skor }\end{array}$ & $\begin{array}{c}\text { Jumlah } \\
\text { Responden } \\
\text { (Orang) }\end{array}$ & $\begin{array}{c}\text { Persentase } \\
(\%)\end{array}$ & $\begin{array}{c}\text { Total } \\
\text { Skor }\end{array}$ \\
\hline Sangat & 5 & 17 & 57 & 85 \\
Kuat & & 8 & 27 & 32 \\
Kuat & 4 & 5 & 16 & 15 \\
Netral & 3 & - & - & - \\
Sedang & 2 & - & - & - \\
Tidak & 1 & & & \\
Kuat & & $\mathbf{3 0}$ & $\mathbf{1 0 0}$ & $\mathbf{1 3 2}$ \\
\hline Total & & &
\end{tabular}


Tabel 9, menunjukkan bahwa 57\% responden (17 orang) sangat kuat dengan $27 \%$ responden ( 8 orang) kuat dan $16 \%$ responden 5 (orang) netral/kurang kuat dengan indeks mengenai pernyataan nomor 5 yaitu pendamping cepat memberikan informasi tentang hal yang baru sehingga interpretasi nilainya tergolong sangat kuat.

Tabel 10. Pendamping Selalu Menciptakan Ide-Ide yang Inovatif dalam Pekerjaan.

\begin{tabular}{lcccc}
\hline $\begin{array}{l}\text { Alternatif } \\
\text { Jawaban }\end{array}$ & $\begin{array}{c}\text { Alternatif } \\
\text { Skor }\end{array}$ & $\begin{array}{c}\text { Jumlah } \\
\text { Responden } \\
\text { (Orang) }\end{array}$ & $\begin{array}{c}\text { Persentas } \\
\text { e } \\
(\%)\end{array}$ & $\begin{array}{c}\text { Total } \\
\text { Skor }\end{array}$ \\
\hline Sangat & 5 & 11 & 37 & 55 \\
Kuat & & & & \\
Kuat & 4 & 10 & 33 & 40 \\
Netral & 3 & 9 & 30 & 27 \\
Sedang & 2 & - & - & - \\
Tidak & 1 & - & - & - \\
Kuat & & & & \\
\hline Total & & $\mathbf{3 0}$ & $\mathbf{1 0 0}$ & $\mathbf{1 2 2}$ \\
\hline
\end{tabular}

Tabel 10, menunjukkan bahwa 37\% responden (11orang) sangat kuat, sedangkan $33 \%$ responden (10 orang) kuat dan 30\% responden dari ( 9 orang) tidak kuat. Karena pernyataan mengenai indeks nomor 6 pendamping selalu menciptakan ide-ide yang inovatif dalam pekerjaan sehingga interpretasi nilainya tergolong sangat kuat.

Tabel 11. Memberikan Motivasi pada

\begin{tabular}{lcccc}
\hline \multicolumn{5}{c}{ Kelompok } \\
$\begin{array}{l}\text { Alternatif } \\
\text { Jawaban }\end{array}$ & $\begin{array}{c}\text { Alternatif } \\
\text { Skor }\end{array}$ & $\begin{array}{c}\text { Jumlah } \\
\text { Responden } \\
\text { (Orang) }\end{array}$ & $\begin{array}{c}\text { Persentase } \\
(\boldsymbol{\%})\end{array}$ & $\begin{array}{c}\text { Total } \\
\text { Skor }\end{array}$ \\
\hline Sangat & 5 & 12 & 40 & 60 \\
Kuat & & & & \\
Kuat & 4 & 9 & 30 & 36 \\
Netral & 3 & 6 & 20 & 18 \\
Sedang & 2 & 3 & 10 & 6 \\
Tidak & 1 & - & - & - \\
Kuat & & & & $\mathbf{1 2 0}$ \\
\hline Total & & $\mathbf{3 0}$ & $\mathbf{1 0 0}$ & \\
\hline
\end{tabular}

Tabel 11, menunjukkan bahwa $40 \%$ responden (12 orang) sangat kuat. Sedangkan $30 \%$ responden (9 orang) kuat dari 20\% reponden(6 orang) netral/cukup kuat dan $10 \%$ responden (3 orang). Mengenai indeks nomor 7 yaitu memberikan motivasi pada kelompok sehingga interpretasi nilai tergolong sangat kuat.

\section{Tingkat Inisiatif}

Tingkat inisiatif merupakan hasrat dalam kemauan untuk mencapai tujuan dan cara berpikir dalam suatu kegiatan yang semakin meningkat.

\section{Tabel 12. Pendamping Bersedia Melakukan Pekerjaan tanpa Perintah Atasan}

\begin{tabular}{lcccc}
\hline $\begin{array}{l}\text { Alternatif } \\
\text { Jawaban }\end{array}$ & $\begin{array}{c}\text { Alternatif } \\
\text { Skor }\end{array}$ & $\begin{array}{c}\text { Jumlah } \\
\text { Responden } \\
\text { (Orang) }\end{array}$ & $\begin{array}{c}\text { Persentase } \\
(\%)\end{array}$ & $\begin{array}{c}\text { Total } \\
\text { Skor }\end{array}$ \\
\hline Sangat & 5 & 10 & 33,33 & 50 \\
Kuat & & & & \\
Kuat & 4 & 20 & 66,67 & 80 \\
Netral & 3 & - & - & - \\
Sedang & 2 & - & - & - \\
Tidak & 1 & - & - & - \\
Kuat & & & & \\
\hline Total & & 30 & 100 & 130 \\
\hline
\end{tabular}

Tabel 12, menunjukkan bahwa $66,67 \%$ responden (20 orang) kuat sedangkan 33,33\% responden (10 orang) sangat kuat. Mengenai indeks pernyataan nomor 8 yaitu pendamping bersedia melakukanpekerjaan tanpa perintah atasan, sehingga interpretasi nilainya tergolong kuat.

Tabel 13. Pendamping Bersedia Memperbaiki Kesalahan

\begin{tabular}{lcccc}
\hline $\begin{array}{l}\text { Alternatif } \\
\text { Jawaban }\end{array}$ & $\begin{array}{c}\text { Alternatif } \\
\text { Skor }\end{array}$ & $\begin{array}{c}\text { Jumlah } \\
\text { Responden } \\
\text { (Orang) }\end{array}$ & $\begin{array}{c}\text { Persentase } \\
(\%)\end{array}$ & $\begin{array}{c}\text { Total } \\
\text { Skor }\end{array}$ \\
\hline Sangat & 5 & 10 & 33,3 & 50 \\
Kuat & 4 & 10 & 33,3 & 40 \\
Kuat & 3 & 7 & 23,3 & 21 \\
Netral & 2 & 3 & 10 & 6 \\
Sedang & 1 & - & - & - \\
Tidak Kuat & & $\mathbf{3 0}$ & $\mathbf{1 0 0}$ & $\mathbf{1 1 7}$ \\
\hline Total & & & &
\end{tabular}

Tabel 13 menunjukkan bahwa 33,3\% responden (10 0rang) sangat kuat 33,3\% responden (10 orang) kuat dan 23,3\% responden (3 orang) netral/cukup kuat. Indeks pernyataan nomor 9 yaitu pendamping bersedia memperbaiki kesalahan sehingga interpretasi nilai tergolong sangat kuat. 


\begin{tabular}{|c|c|c|c|c|}
\hline & $\begin{array}{l}\text { yang } \\
\text { Kelompo }\end{array}$ & reatif & $\mathbf{k}$ & ajuan \\
\hline $\begin{array}{l}\text { Alternatif } \\
\text { Jawaban }\end{array}$ & $\begin{array}{l}\text { Alternatif } \\
\text { Skor }\end{array}$ & $\begin{array}{c}\text { Jumlah } \\
\text { Responden } \\
\text { (Orang) }\end{array}$ & $\begin{array}{c}\text { Persentase } \\
(\%)\end{array}$ & $\begin{array}{l}\text { Total } \\
\text { Skor }\end{array}$ \\
\hline $\begin{array}{l}\text { Sangat } \\
\text { Kuat }\end{array}$ & 5 & 21 & 70 & 105 \\
\hline Kuat & 4 & 9 & 30 & 36 \\
\hline Netral & 3 & - & - & - \\
\hline Sedang & 2 & - & - & - \\
\hline $\begin{array}{l}\text { Tidak } \\
\text { Kuat }\end{array}$ & 1 & - & - & - \\
\hline Total & & 30 & 100 & 141 \\
\hline
\end{tabular}

Tabel 14, menunjukkan bahwa $70 \%$ responden (21 orang) sangat kuat dan 30\% responden (9 orang) kuat. Mengenai indeks pernyataan nomor 10 yaitu pendamping mampumemberikan ide yang kreatif untuk kemajuan kelompok sehingga interpretasi nilainya tergolong sangat kuat.

Tabel 15. Selalu Menciptakan Sesuatu yang Baru

\begin{tabular}{lcccc}
\hline $\begin{array}{l}\text { Alternatif } \\
\text { Jawaban }\end{array}$ & $\begin{array}{c}\text { Alternatif } \\
\text { Skor }\end{array}$ & $\begin{array}{c}\text { Jumlah } \\
\text { Responden } \\
\text { (Orang) }\end{array}$ & $\begin{array}{c}\text { Persentase } \\
(\%)\end{array}$ & $\begin{array}{c}\text { Total } \\
\text { Skor }\end{array}$ \\
\hline Sangat & 5 & 6 & 20 & 30 \\
Kuat & & 24 & 80 & 96 \\
Kuat & 4 & - & - & - \\
Netral & 3 & - & - & - \\
Sedang & 2 & - & - & - \\
Tidak & 1 & & & \\
Kuat & & $\mathbf{3 0}$ & $\mathbf{1 0 0}$ & $\mathbf{1 2 6}$ \\
\hline Total & & &
\end{tabular}

Tabel 15, menunjukkan bahwa $20 \%$ responden(6 orang) sangat kuat dan $80 \%$ responden (24 orang) kuat. Mengenai indeks pernyataan nomor 11 yaitu selalu menciptakan sesuatu yang baru, sehingga interpretasi nilainya tergolong kuat.

\section{Tingkat Mutu Pekerjaan}

Mutu pekerjaan meningkat merupakan sumber daya manusia perlu dikembangkan secara terus menerus dalam pekerjaan untuk menghasilkan kerja yang bermutu dalam pekerjaan kelompok.
Tabel 16. Motivasi Memberikan Semangat Pada Pendamping yang Bekerja

\begin{tabular}{lcccc}
\hline $\begin{array}{l}\text { Alternatif } \\
\text { Jawaban }\end{array}$ & $\begin{array}{c}\text { Alternatif } \\
\text { Skor }\end{array}$ & $\begin{array}{c}\text { Jumlah } \\
\text { Responden } \\
\text { (Orang) }\end{array}$ & $\begin{array}{c}\text { Persentase } \\
(\boldsymbol{\%})\end{array}$ & $\begin{array}{c}\text { Total } \\
\text { Skor }\end{array}$ \\
\hline Sangat & 5 & 15 & 50,00 & 75 \\
Kuat & & 8 & 26.67 & 32 \\
Kuat & 4 & 6 & 20,00 & 18 \\
Netral & 3 & 1 & 3,33 & 2 \\
Sedang & 2 & - & - & - \\
Tidak Kuat & 1 & $\mathbf{3 0}$ & $\mathbf{1 0 0}$ & $\mathbf{1 2 7}$ \\
\hline Total & & & &
\end{tabular}

Tabel 16, menunjukkan bahwa 50\% responden (15 orang) sangat kuat dan $27 \%$ responden ( 8 orang) kuat $20 \%$ responden (6 orang) netral/cukup kuat dan 3,3\% responden (1 orang) sedang. Dengan indeks mengenai pernyataan nomor 12 motivasi pendamping memberikan semangat pada anggota kelompok yang bekerja, sehingga interpretasi nilainya tergolong sangat kuat.

Tabel 17. Pendamping Cepat Memastikat Kualitas Secara

\begin{tabular}{lcccc}
\hline $\begin{array}{l}\text { Alternatif } \\
\text { Jawaban }\end{array}$ & $\begin{array}{c}\text { Alternatif } \\
\text { Skor }\end{array}$ & $\begin{array}{c}\text { Jumlah } \\
\text { Responden } \\
\text { (Orang) }\end{array}$ & $\begin{array}{c}\text { Persentase } \\
(\%)\end{array}$ & $\begin{array}{c}\text { Total } \\
\text { Skor }\end{array}$ \\
\hline Sangat & 5 & 23 & 76,67 & 115 \\
Kuat & & & & \\
Kuat & 4 & 6 & 20,00 & 24 \\
Netral & 3 & 1 & 3,33 & 3 \\
Sedang & 2 & - & - & - \\
Tidak & 1 & - & - & - \\
Kuat & & & & \\
\hline Total & & $\mathbf{3 0}$ & $\mathbf{1 0 0}$ & $\mathbf{1 4 2}$ \\
\hline
\end{tabular}

Tabel 17 menunjukkan bahwa 76,67\% responden (23 orang) sangat kuat sedangkang $20 \%$ responden (6 orang) kuat dengan pernyataan indeks nomor 13 yaitu pendamping cepat memastikan kualitas secara efektif yang meningkat, sehingga interpretasi nilainya tergolong sangat kuat.

Tabel 18. Pendamping Menjamin Kualitas Atas \begin{tabular}{lcccc}
\multicolumn{4}{c}{ Kebutuhan Kelompok } \\
\hline Alternatif & Alternatif & Jumlah & Persentase & Total \\
Jawaban & Skor & $\begin{array}{c}\text { Responden } \\
\text { (Orang) }\end{array}$ & $(\%)$ & Skor \\
& & &
\end{tabular}

\begin{tabular}{lcccc}
\hline Sangat Kuat & 5 & 19 & 63,33 & 95 \\
Kuat & 4 & 6 & 20,00 & 24 \\
Netral & 3 & 5 & 16,67 & 15 \\
Sedang & 2 & - & - & - \\
Tidak Kuat & 1 & - & - & - \\
\hline Total & & $\mathbf{3 0}$ & $\mathbf{1 0 0}$ & $\mathbf{1 3 4}$ \\
\hline
\end{tabular}


Agri-SosioEkonomi Unsrat, ISSN 1907-4298, Volume 13 Nomor 3A, November 2017 : 385 - 396

Tabel 18, menunjukkan bahwa $63,3 \%$ responden (19 orang) sangat kuat. Sedangkan $20 \%$ responden (6 orang) kuat dan $16,67 \%$ responden $(5$ orang) netral/cukup setuju dengan pernyataan indeks nomor 14 yaitu pendamping menjamin kualitas atau kebutuhan kelompok, sehingga interpretasi nilainya tergolong sangat kuat.

\section{Tingkat Mematuhi Jam Kerja}

Tingkat mematuhi jam kerja merupakan kegiatan organisasi yang bersifat individu dalam kelompok dan sering dikatakan disiplin dalam kelompok.

Tabel 19. Pendamping Datang Tepat Waktu dalam Bekerja

\begin{tabular}{lcccc}
\hline $\begin{array}{l}\text { Alternatif } \\
\text { Jawaban }\end{array}$ & $\begin{array}{c}\text { Alternatif } \\
\text { Skor }\end{array}$ & $\begin{array}{c}\text { Jumlah } \\
\text { Responden } \\
\text { (Orang) }\end{array}$ & $\begin{array}{c}\text { Persentase } \\
\mathbf{( \% )}\end{array}$ & $\begin{array}{c}\text { Total } \\
\text { Skor }\end{array}$ \\
\hline Sangat Kuat & 5 & 22 & 73,33 & 110 \\
Kuat & 4 & 7 & 23,33 & 28 \\
Netral & 3 & 1 & 3,33 & 3 \\
Sedang & 2 & - & - & - \\
Tidak Kuat & 1 & - & - & - \\
\hline Total & & $\mathbf{3 0}$ & $\mathbf{1 0 0}$ & $\mathbf{1 4 1}$ \\
\hline
\end{tabular}

Tabel 19, menunjukkan bahwa $73,33 \%$ responden (22 orang) sangat kuat dan $23,33 \%$ responden ( 7 orang) kuat $3,33 \%$ responden (1orang) netral/cukup setuju dengan indeks mengenai pernyataan nomor 15 pendamping datang tepat waktu dalam bekerja sehingga interpretasi nilainya tergolong sangat kuat.

Tabel 20, menunjukkan bahwa 50\% responden (15 orang) sangat kuat sedangkan $43,33 \%$ responden (13 orang) kuat dan $7 \%$ responden (2 orang) netral. Dengan indeks pernyataan nomor 16 yaitu pendamping selalu mentaati aturan yang ada pada setiap kelompok sehingga interpretasi nilainya tergolong sangat kuat.
Tabel 20. Pendamping Selalu Mentaati Aturan yang ada pada setiap Kelompok

\begin{tabular}{lcccc}
\hline $\begin{array}{l}\text { Alternatif } \\
\text { Jawaban }\end{array}$ & $\begin{array}{c}\text { Alternatif } \\
\text { Skor }\end{array}$ & $\begin{array}{c}\text { Jumlah } \\
\text { Responden } \\
\text { (Orang) }\end{array}$ & $\begin{array}{c}\text { Persentase } \\
(\%)\end{array}$ & $\begin{array}{c}\text { Total } \\
\text { Skor }\end{array}$ \\
\hline Sangat & 5 & 15 & 50,00 & 75 \\
Kuat & & & & \\
Kuat & 4 & 13 & 43,33 & 52 \\
Netral & 3 & 2 & 6,67 & 6 \\
Sedang & 2 & - & - & - \\
Tidak & 1 & - & - & - \\
Kuat & & & & \\
\hline Total & & $\mathbf{3 0}$ & $\mathbf{1 0 0}$ & $\mathbf{1 3 3}$ \\
\hline
\end{tabular}

Tabel 21, menunjukkan bahwa $50 \%$ responden (15 orang) sangat kuat $30 \%$ responden (9 orang) kuat dan $20 \%$ responden (6 orang) netral cukup setuju. Karena indeks pernyataan nomor 17 yaitu pendamping masuk kerja tepat waktu sehingga interpretasi nilainya tergolong sangat kuat

Tabel 21. Pendamping Masuk Kerja Tepat Waktu

\begin{tabular}{lcccc}
\hline $\begin{array}{l}\text { Alternatif } \\
\text { Jawaban }\end{array}$ & $\begin{array}{c}\text { Alternatif } \\
\text { Skor }\end{array}$ & $\begin{array}{c}\text { Jumlah } \\
\text { Responden } \\
\text { (Orang) }\end{array}$ & $\begin{array}{c}\text { Persentase } \\
(\mathbf{\%})\end{array}$ & $\begin{array}{c}\text { Total } \\
\text { Skor }\end{array}$ \\
\hline Sangat & 5 & 15 & 50 & 75 \\
Kuat & 4 & 9 & 30 & 36 \\
Kuat & 3 & 6 & 20 & 18 \\
Netral & 2 & - & - & - \\
Sedang & 1 & - & - & - \\
Tidak & & & $\mathbf{1 0 0}$ & $\mathbf{1 2 9}$ \\
Kuat & \multicolumn{5}{c}{}
\end{tabular}

\section{Rekapitulasi Indeks Motivasi Pendamping Kelompok Tani pada Masing-Masing Indikator dan Interpretasi Hasil}

Penelitian untuk mengukur motivasi pendamping terhadap pemberdayaan kelompok tani yang diterapkan dengan 17 indikator sebagai tolak ukur ditunjukkan pada Tabel 22.

Tabel 22. Rekapitulasi Motivasi Pendamping, Total Skor, Indeks Motivasi dan Interpretasi Hasil

\begin{tabular}{|c|c|c|c|c|}
\hline No & Motivasi Pendamping & Total Skor & Indeks Motivasi & Interpretasi \\
\hline 1. & Pendamping cepat menjawab & 128 & 85,33 & Sangat kuat \\
\hline 2. & Pendamping cepat menyelesaikan tugas atas standar & 145 & 63,33 & Sangat kuat \\
\hline 3. & Pendamping cepat menyelesaikan masalah & 135 & 90 & Sangat kuat \\
\hline 4. & Pendamping cepat mengambil keputusan dalam kelompok & 131 & 87,33 & sangat kuat \\
\hline 5. & Pendamping selalu memberikan informasi tentang hal yang baru & 132 & 88 & Sangat kuat \\
\hline 6. & Pendamping selalu menciptakan ide-ide yang inovatif dalam pekerjaan. & 122 & 81,33 & Sangat kuat \\
\hline 7. & Memberikan motivasi pada kelompk tani & 124 & 82,66 & Sangat kuat \\
\hline 8. & Pendamping bersedia melakukan pekerjaan tanpa perintah atasan. & 130 & 86,66 & Kuat \\
\hline 9. & Pendamping bersedia memperbaiki kesalahan & 117 & 78 & Sangat kuat \\
\hline 10. & Mampu memberikan ide yang kreatif untuk kemajuan kelompok & 141 & 94 & Sangat kuat \\
\hline 11. & Selalu menciptakan sesuatu yang baru & 126 & 84 & Sangat kuat \\
\hline 12. & Motivasi memberikan semangat pada pendamping yang bekerja. & 127 & 84,66 & Sangat kuat \\
\hline 13 & Pendamping cepat memastikan kualitas secara efektif yang meningkat. & 142 & 94,66 & Sangat kuat \\
\hline 14 & Pendamping menjamin kualiatas dan kebutuhan kelompok. & 134 & 89,33 & Sangat kuat \\
\hline 15 & Pendamping datang tepat waktu dalam bekerja. & 141 & 94 & Sangat kuat \\
\hline 16 & Pendamping selalu menaati aturan yang ada pada setiap kelompok. & 133 & 88,66 & Kuat \\
\hline 17 & Pendamping cepat masuk kerja tepat waktu & 131 & 87,33 & Sangat kuat \\
\hline
\end{tabular}


Tabel 22, menunjukkan bahwa semua indikator mendapatkan skor pada indeks yang tergolong kuat. Walaupun pada indikator 17 yakni aspek konatif hanya skor 98,3 persen namun masih tergolong sangat kuat. Hal ini menunjukkan bahwa dalam pendamping tergolong sangat kuat. Untuk mengetahui letak motivasi pendamping terhadap pemberdayaan kelompok tani, maka perlu dihitung jumlah keseluruhan skor pada setiap kriterium, dimana sesuai hasil penelitian ini skor mencapai 2,239 Pada penelitian ini, jumlah skor ideal (skor tertinggi), yaitu 2.550 (tinggi) dan jumlah skor terendah yaitu 510 (rendah). Berdasarkan data yang dihimpun dari sebanyak 17 instrumen pernyataan yang diajukan kepada 30 responden, maka diperoleh total skor 2.550 dengan letak indeks ditentukan berdasarkan skala likert berikut :

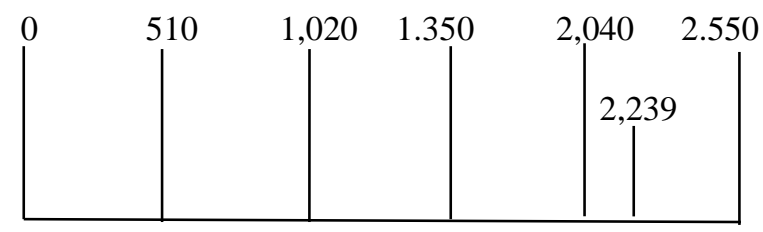

Sangat Buruk Buruk Kurang Baik Baik Sangat Baik

Secara persentase, angka indeks motivasi pendamping terhadap pemberdayaan kelompk tani :

Tingkat Pendamping = $\frac{\text { Jumlah Skor Hasil Pengumpulan Data }}{\text { Jumlah Skor Ideal (Sangat kuat) }} \times 100 \%$

Dengan Interpretasi nilai :

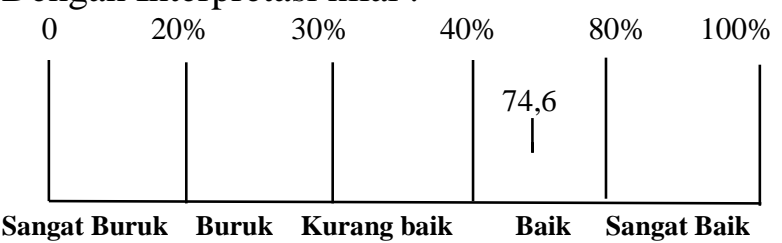

\section{Keterangan:}

Angka 0\% = Nol persen

Angka 20\% = Sangat buruk

Angka 30\% $=$ Buruk

Angka 40\% = Kurang baik

Angka 80\% =Baik

Angka 100\% = Sangat Baik

Angka 74,6\% = Adalah hasil analisis dari jumlah skor pengumpulan data dan jumlah skor ideal.

\section{KESIMPULAN DAN SARAN}

\section{Kesimpulan}

Berdasarkan hasil penelitian dapat disimpulkan bahwa motivasi pendamping sangat berperan pada keseluruhan tugas pokok dan fungsi. Pendamping berperan dalam pemberdayaan kelompok tani baik pada tingkat permula maupun lanjut dalam kegiatan. Kendala yang dihadapi oleh kelompok tani adalah kurangnya koordinasi sehingga pendamping kelompok tani yang sulit dalam merubah pola pikir petani karena petani yang masih terpaku dan mengharapkan bantuan yang diberikan, sehingga petani perlu melakukan pendamping kelompok tani yang insentif terhadap kelompok tani. Kendala yang di hadapi oleh kelompok tani di Desa Kinunang kecamatan likupang timur adalah kelompok tani yang masih takut menerima resiko atau kegagalan dalam prodoksi, sehingga belum bisa menerima teknologi- teknologi yang baru sehingga petani lebih memilih untuk mengusahakan tanamannya dengan cara sendiri.

\section{Saran}

Berdasarkan penelitian yang telah dilakukan, maka saran yang dapat diberikan kepadapendampingyaitu:Perlu meningkatkan motivasiu (1) untuk mendampingi kelompok tani yang belum mandiri kearah mandiri sehingga kelompok tani lebih baik dalam pengambilan keputusan sehingga menjadi kelompok tani yang lebih maju. (2) Perlu meningkatkan komunikasi antara pendamping dan kelompok tani.

\section{DAFTAR PUSTAKA}

Alma Buchari. 2010. Kewirausahaan. Alfabeta. Bandung.

Anonimous, 2009. Pengertian-Pengertian K elompok Tani, diakses melaluihttp://site.google.com/site, pada tanggal 17 September 2012, Fungsi Kelompok tani, Diakses melalui http://site.google.com/site, pada tanggal 17 September 2012. Pengertian Pemberdayaan dan Kemandirian. http://site.google.com/site, pada tanggal 27 September 2012. 
Anoraga, Pandji. 2001. Psikologi Kerja. PT. Rineka Cipta. Jakarta.

Culligan, M. J., 1996. Manajemen Back To Basic (terjemahan). Jakarta. Penerbit Spektrum.

Gouzaly, Saydam, 2000. Manajemen Sumber Daya Manusia, Gunung Agung, Jakarta.

Gustiyah, Raikan. 2009. Analisis Faktor-Faktor yang Mempengaruhi Motivasi Kerja Penyuluhan Perindustrian pada Kantor Perindustrian dan Perdagangan Kota Medan.Tesis.

Hadari, Nawawi, 2001, Metode Penelitian Bidang Sosial,Gajah Mada University Press, Yogyakarta.

Hermanto, 2006, Rancangan Kelembagaan Petani dalam Implementasi Prima Tani, Jambi.

Hubeis, A.T. 2000. Suatu Pikiran Tentang Kebijakan Pemberdayaan Kelembagaan Petani. Deptanhut. Jakarta

Khairuddin. 1992. Pembangunan Masyarakat Tinjauan Aspek Sosial Ekonomi dan Perencanaan. Liberty. Jakarta.

Leibo, J., 2007. Sosiologi Pedesaan, Yogyakarta : Andi Offset.

Malthis, R.L dan Jackson. 2001. Manajemen Sumber Daya Manusia. Salemba Empat. Jakarta.

Mardianto, Adi. 2012. Recruitmen Analysis. Pinasthika. Jakarta.

Mardikanto, T. 2009. Sistem Penyuluhan Pertanian. Sebelas Maret University Press Surakarta.

Mardikanto, T. 1996. Penyuluhan Pembangunan Kehutanan. Departemen Kehutanan. Jakarta.

Munandar, Anshar S. 2001. Psikologi Industri dan Organisasi. Edisi Pertama. UIP.
Nasikun, J. 1995. Mencari Suatu Strategi Pembangunan Masyarakat Desa Berparadigma.

Peraturan Menteri Dalam Negeri Republik Indonesia.Nomor 7 Tahun 2007 tentang Kader Pemberdayaan Masyarakat.Bandung. Fokus Media.

Rivai, Veithzal. 2004. Manajemen Sumber Daya Manusia Untuk Perusahaan.PT Raja Grafindo Persada. Jakarta.

Riyanti, B. D dan Prabowo, H. 1998.Psikologi Umum 2 (Seri Diktat Kuliah). Gunadarma. Jakarta.

Robbins dan Judge. 2007. Perilaku Organisasi. Salemba Empat. Jakarta. Salim.

Robbins, S. 1996. Perilaku Organisasi, Konsep, Kontroversi Aplikasi (Terjemahan). Jakarta. Penerbit Prenhallindo.

Robbins, Stephen. P. dan Mary Coulter. 2005. Manajemen.PT Indeks Kelompok Gramedia. Jakarta.

Salim, Emil. 1996. Aspek Sikap Mental Dalam Manajemen Sumberdaya Manusia. Ghalia Indonesia. Jakarta.

Sayuti, 2006, Motivasi dan faktor-faktor yang mempengaruhi. Penerbit Ghalia Indonesia, Jakarta.

Siagian, P. 1995. Teori Motivasi dan Apliksi.

Sudjana. 2001. Pendidikan Luar Sekolah. Bandung: Falah Production.

Sumaryadi.2005. Perencanaan Pembangunan Daerah Otonom dan Pemberdayaan Masyarakat. Jakarta: Citra Utama.

Sunyoto Usman. 2004. Pembangunan dan Pemberdayaan Masyarakat, Yogyakarta Pustaka Pelajar.

Sutikno, M, 2012. Manajemen Pendidikan. Holistica. Lombok. Rineke Cipta. Jakarta. 
Sutoro Eko, 2002, Pemberdayaan Masyarakat Desa, Materi Diklat Pemberdayaan Masyarakat Desa, yang diselenggarakan Badan Diklat Provinsi Kaltim, Samarinda, Desember 2002.

Widjajanti, Kesi. 2011. Model Pemberdayaan Masyarakat. Jurnal Pembangunan. Vol. 12, (No 01) : 15-27.
Winardi, 2004.Motivasi dan Pemotivasian Dalam Manajemen.PT Raja Grafindo Jakarta.

Winardi.1992. Manajemen Perilaku Organisasi. PT Citra Aditya Bakti. Bandung.

Zubaedi. 2013. Pengembangan Masyarakat, Wacana dan Praktik, Kencana Prenada Media Group, Jakarta. 